\title{
Assessing the Risk Relevance of Accounting Variables in Diverse Economic
}

\section{Conditions}

by

Mark Brimble*

and

\author{
Allan Hodgson ${ }^{+}$
}

\author{
*Griffith Business School, Griffith University, Brisbane, Australia 4111 \\ ${ }^{+}$The Amsterdam graduate Business School, The University of Amsterdam, \\ 1018 WB, The Netherlands
}

This paper examines the association between accounting information and systematic (beta) risk. We extend previous research by using an updated data set, a range of risk measures that adjust for different market and time-varying conditions, and by examining whether the long-run association has changed over time. Results indicate a consistently strong association between accounting variables and systematic risk, with up to $67 \%$ predominantly explained by accounting variables that proxy for operational and growth risk. The strength of the association, however, varies according to industry and firm size. Results are robust to different market conditions, including mean reverting risk, time varying risk and financial leverage, but with a lower association in thin trading conditions. In an out-of-sample test we found that an accounting variable risk model is superior in predicting forward time-varying systematic risk proxied by an M-GARCH beta. Finally, we determined that the risk relevance of accounting information has not significantly declined over the past 30years, contrary to other research that shows a decline in the price relevance of accounting information over the same period.

Key Words: accounting risk relevance, M-GARCH beta, accounting beta.

We would like to thank participants at the 2002 Australasian Banking and Finance Conference, colleagues at the Griffith Business School, Marc DeCeuster, XXXXX and an anonymous referee for a number of constructive comments. 


\subsection{Introduction}

The seminal research into the risk relevance of accounting information was explored in the early studies of Beaver, Kettler and Scholes (1970) in the US and Castagna and Matolcsy (1978) in Australia, but curiously this line of esearch appears to have largely dissipated. Risk management, however, is an important component of a firm's corporate governance and this is particularly the case for small, undiversified firms. Furthermore, beta as a traded price surrogate for systematic risk is not directly measurable through price movements for firms that are not listed, and this fact provides difficulties when estimating the cost of capital and relative risk structures of unlisted firms. Prior research has generally found that accounting variables have valuable information for risk assessment and, hence, research that relates accounting variables to measures of systematic risk has information for both investors and managers as a surrogate to market based estimates and predictions, and in the constructive formulation of accounting policies.

In a review of the literature Ryan (1997) discusses five motivations for relating accounting research to measures of systematic risk: (i) the development of more efficient ex post risk measures, (ii) the determination of actual risk determinants rather than just determining the level of risk, (iii) overcoming the problem that conventional ex-post measures cannot be used for non- listed entities, ${ }^{i}$ initial public offering firms, or those that do not have sufficient trading history, (iv) as instrumental variables to reduce the noise found in traditional risk estimates that rely on historical security returns, and (v) the development of trading strategies and the construction of portfolios with the desired level of risk. Other potential extensions include refinements to beta (Laveren et al., 1997), controlling for different market conditions (Ismail and Kim, 1989), the incremental use of other accounting variables (Ismail and Kim, 1998), and altering the estimation of beta for time variance (Faff, Hodgson and Saudagaran, 2001). In effect, using accounting data as a surrogate for security prices or to refine price based estimates of systematic risk.

A major objective of prior research that relates accounting variables to the assessment of risk was to determine the relevant key accounting variables. The obtained results were then argued to be an aid in suggested amendments to financial disclosure regulations to ensure that the risk relativity of financial information is adequately 
disclosed to investors, thus assisting them in asset allocation decisions. Some authors such as Scholes (1996) and Ryan (1997) have specifically argued for the development of a set of accounting risk standards to overcome the inflexibility of the traditional historic cost accounting systems that concentrates on static valuations. For example, Ryan (1997) proposes that the current accounting system can evolve to provide more informative information to financial statement users to enable them to assess the risk of a firm.

We contribute to this previous research in several ways. First, by using an association study, we establish those accounting variables (classified into operating, financing and growth variables) that are rela ted to systematic risk derived from the standard market model. These results are then compared to prior research dating back over 40 -years in order to evaluate whether the relevant accounting variables have changed over time. Second, in addition to the satic market model, we utilise a number of proxies for systematic risk that capture the time varying nature of risk as well as a number of institutional and firm specific factors. For example, calculating betas that adjust for mean reversion, thin trading, financial leverage and time variance as well as decomposing the data into different industries and firm size. In this way we analyse whether the determined accounting variables are robust across different economic settings and are able to accommodate dynamic environments. Third, we assess the out-of-sample ability of accounting variables to predict a time varying multivariate GARCH measure of systematic risk against a random walk model. Fourth, we determine whether the explanatory power of accounting variables for systematic risk has changed over time. The study utilises accounting data from Australia over a 40year time period and thus also provides a study of a small country setting outside the US.

Briefly, our results show a consistently strong association between accounting variables and systematic risk with risk relevant information mainly contained in operational and growth accounting variables. This result is consistent with prior Australian research with the exception of financial leverage and with US studies with the exception of the dividend payout ratio. The strength of the association of accounting variables with systematic risk varies according to industry and firm size and, in an out-of-sample test, we find that an accounting variable risk model is 
superior in predicting forward time- varying systematic risk (M-GARCH). Finally, we determine that the risk relevance of accounting information has not significantly declined over the past 30-years contrary to prior research that indicates the price relevance accounting data has declined (Collins, Maydew and Weiss, 1997; Francis and Shipper, 1999). In general, our results support the hypothesis that accounting variables are robust in handling dynamic and diverse economic conditions over time.

The remainder of this paper is set out as follows. The next section examines the background literature, section three describes the data and method with the results summarised in section four. Section five contains the summary and conclusions.

\subsection{Background}

Systematic risk refers to the variation of a firm's price returns that are associated with factors common to the market that cannot be diversified away. A common method of estimating the systematic risk of a firm is to use the capital asset pricing model (CAPM) (Sharpe, 1964; and Lintner, 1965) to calculate a time-invariant or moving average beta. Subsequently, a number of accounting studies have attempted to identify accounting variables that can be linked to this measure of beta risk. A key issue is the theoretical role that certain accounting variables are hypothesised to play in determining systematic risk (Ryan, 1997; Laveren et al., 1997) and, hence, a model that theoretically relates systematic risk to accounting variables is presented in Figure 1 (Penman, 2001).

This model explains systematic risk as a dual function of the return on common equity risk (ROCE) and growth risk, similar in concept to the familiar DuPont type analysis. ROCE risk is further broken down into operating risk and financing risk whereby financing risk is split into financial leverage risk and borrowing cost risk. Furthermore, operating risk is a function of profit margin, asset turnover and operating liability leverage risk; where profit margin risk is further still a function of expense risk and operating leverage risk. Hence, this framework provides a theoretical overview of the interrelationships between accounting ratios and illustrates the role of accounting information in estimating risk.

\section{Insert Figure 1 About Here}


A number of studies extended the above theoretical model by attempting to identify a set of risk-related accounting variables that can be empirically linked to systematic risk. The seminal empirical work in this area, Beaver, Kettler and Scholes (1970), examined seven accounting variables including dividend payout, asset growth, financial leverage, asset size, current ratio, variance in earnings and accounting beta. They provided evidence to show that accounting variables are useful in the prediction of systematic risk, in so far as the best fit accounting model is a better predictor of systematic risk than current beta, that is a naïve forecasting model. Moreover, their best fit model was relatively parsimonious and incorporated only three of the seven accounting variables: dividend payout ratio (negative), asset growth (positive), and earnings variability (positive), but these explained 45 percent of the cross sectional variation in market beta. The Beaver, Kettler and Scholes (1970) paper provided the foundation for subsequent research during the 1970's that expanded upon the seven accounting variables examined. For example, a set of thirty three accounting and nonaccounting variables ${ }^{\mathrm{ii}}$ were used by Rosenberg and McKibben (1973) to determine an accounting measure of systematic risk. Their final model incorporated thirteen ${ }^{\text {iii }}$ of the thirty three variables examined and explained thirty three percent of systematic beta. This period can be categorised as inductive driven data research with the number of accounting variables examined differing greatly, but with some studies using up to one hundred and one variables (Rosenberg and Marathe, 1975).

Other researchers concentrated on specific variables related to tightly argued theoretical constructs that tended to be highly specific and narrowly defined. For example, research based on operating leverage (Lev, 1974), variability of sales and financial leverage (Lev and Kunitzky, 1974), turnover and coverage ratios (Bildersee, 1975), managerial actions (Bildersee, 1975), industry effect (Lev, 1974; Lev and Kunitzky, 1974; Bildersee, 1975), financial structure (Hill and Stone, 1980), and different methods of calculating accounting beta (Beaver and Manegold, 1975). Whilst, the general conclusion of these studies was that accounting variables contain information related to risk, there is little agreement over which accounting variables are more risk relevant and even less discussion on how to benchmark these variables, with a static CAPM systematic risk proxy adopted as the given benchmark. An exception is a study of the Belgium stock market by Laveren et al. (1997) that 
compared the ability of accounting variables to estimate both a levered and an unlevered beta. ${ }^{\text {iv }}$

Recent research has also extended the accounting variables by examining off-balance sheet accounting items. For example, McAnally (1996) found that credit-risk related instruments are positively related to risk and market related instruments ${ }^{\mathrm{v}}$ are negatively related to risk. Cheon, Duchac and Goldberg (1996) added to this literature by examining foreign exchange and interest rate derivatives and found a significant negative association between these variables and beta.

In terms of the Australian evidence there is only one published paper that addresses this research issue. Castagna and Matolcsy (1978) examined one hundred and forty Australian firms between 1967 and 1976 and investigated seven accounting variables ${ }^{\mathrm{vi}}$ and one non-accounting variable (trading volume). The results were similar to the US studies with the exception of firm size, which illustrated a positive association with beta where a negative association had been found in the US. Several reasons for this were suggested including: (i) larger firms in Australia engage in riskier operations than small firms, (ii) sampling issues where the sample included primarily large firms, and (iii) the results are time period specific.

In summary, a variety of accounting variables have been examined, in association and predictive studies, with results indicating that the accounting data can explain up to forty five percent of the cross-sectional variation in systematic beta and that accounting models may be able to outperform predictions from a naïve beta model. As Ryan (1997) points out, there is substantial scope for further research, and theoretical development of the proposition that accounting variables can significantly explain and proxy for systematic risk. Our extensions are to use an updated data set, to incorporate a range of systematic risk measures (some of which are more appropriate to a small economy setting) and then to compare them with the association from the accounting variables. We also address some of the concerns expressed by Castagna and Matolcsy (1978) regarding firm size and whether the results are time specific. 


\subsection{Data and Variables Used}

The data used for the first part of the study is Australian listed companies available on Datastream over the period 1991-2000 inclusive with a complete set of the required market price and accounting data available over this period. ${ }^{\text {vii }}$ These filters resulted in a final data set that comprised 129 firms and 1290 firm year observations. ${ }^{\text {viii }}$ A check of the industry distribution showed that the data is generally representative of the Australian all ordinaries index.

\section{Beta Estimation}

The first part of this study analyses whether accounting data has a significant association with systematic risk. We extend prior research by not assuming one (static) proxy for risk; by estimating five forms of beta risk, drawing on the methods used in the prior literature and utilising a monthly return holding period (per Alexander and Chervany, 1980). In this way we assess whether accounting risk proxies are robust to different measures of systematic risk and therefore can be used in dynamic situations or across differing institutional or trading settings. The five systematic betas are:

1. The OLS/Market Beta $\left.\beta_{O L S i}\right)$ : Calculated using the static market model by ordinary least squares (OLS) regression. The standard specification of the market model is as follows:

$$
R_{i t}=\alpha_{i}+\beta_{i} R_{m t}+\varepsilon_{i t}
$$

where $R_{i t}$ is the realised return for stock $i$ in the period $t, \alpha_{i}$ is the intercept term for asset $i, \beta_{i}$ is the coefficient of return on asset $i$ to stock market returns, $R_{m t}$ is the realised return on the stock market index for period $t$, and $\varepsilon_{i t}$ is the residual term.

2. The Thin Trading Beta $\left(\beta_{S W i}\right)$ : The literature proposes several alternative methods of correcting for thin trading biases (Dimson, 1979) and generally concludes that the most appropriate method will depend on market characteristics. The most common method utilised is the original aggregated coefficients method by Scholes and Williams (1977) and we adopt this approach. It is defined as: 


$$
\beta_{S W i}=\frac{\beta_{i}^{-1}+\beta_{i}+\beta_{i}^{+1}}{\left(1+2 \rho_{m}^{-}\right)}
$$

where $\beta_{S W i}$ is the Scholes-Williams beta estimate, $\beta_{i}^{-1}$ is the beta estimate from the OLS regression of $R_{i t}$ on $R_{m t-1}, \beta_{i}$ is the beta estimate from the standard market model, $\beta_{i}^{+1}$ is the beta estimate from the OLS regression of $R_{i t}$ on $R_{m t+1}$, and $\rho_{m}$ is the first order serial correlation coefficient of market return.

3. The Central Tendency Beta $\left(\beta_{V A S i}\right)$ : Calculated using the Vasicek (1973) adjustment which is a commonly used method to adjust for central tendency by applying a Bayesian estimation technique. This is computed as follows:

$$
\beta_{i}^{V}=\frac{\beta^{\prime} / s^{2} \beta^{\prime}+\beta^{\prime} / s^{2} \beta_{i}}{1 / s^{2} \beta^{\prime}+1 / s^{2} \beta_{i}}
$$

where $\beta_{i}^{V}$ is the Vasicek beta estimate, $\beta_{i}$ is the OLS beta for stock $i$, and $s^{2} \beta_{i}$ is its estimated variance, $\beta^{\prime}$ is the unweighted market average of OLS betas and $s^{2} \beta$ ' is the cross-sectional variance of OLS betas of different stocks.

4. The Unlevered Beta $\left(\beta_{U N L E V i}\right)$ : Calculated using the Laveren et al. (1996) book value method. This method postulates a theoretical link between beta and financial leverage, whereby a firm with debt in its capital structure will have a higher relative systematic risk. Consequently, there is a theoretically positive relationship between beta, as a measure of systematic risk, and financial leverage.

Beta can be unlevered using one of several techniques found in the research of Bowman (1979), Laveren et al. (1996) and Hill and Stone (1980). Laveren et al., (1996) examined both the Hamada and the Laveren et al. methods of unlevering beta and concluded that no statistically significant differences arise between the different methods. We apply the book values approach defined as: 


$$
\beta_{U}=\beta_{l} \frac{E}{V}
$$

where $\beta_{U}$ is the unlevered beta, $\beta_{L}$ is the levered beta, $E$ is the book value of common equity and $V$ is total market value.

5. The Time Varying GARCH Beta $\left.\beta_{G A R C H i}\right)$ : calculated using the Bollerslev (1990) multivariate constant correlation M-GARCH estimation. Bollerslev (1990), based upon observation that risk is dynamic over time, constructed a conditional time varying beta series based on conditional variance and covariance estimates produced by a GARCH $(1,1)$. In this model conditional variances and covariances are time varying with shocks from both the market index proxy and the firm lasting one period. A restrictive assumption is that the correlation between conditional variances through time is constant, but this significantly reduces the number of parameters required to be estimated and the probability that convergence occurs (see Faff, Hodgson and Saudagaran, 2001). We construct a time series of conditional betas as follows:

$$
\beta_{i t}^{G}=\frac{\rho_{i m} \sigma_{i t}}{\sigma_{m t}}
$$

where:

$$
\sigma_{i t}^{2}=c_{1}+a_{11} \varepsilon_{i t-1}^{2}+b_{11} \sigma_{i t-1}^{2}
$$

Hence, these five estimates of systematic risk provide benchmarks across varying institutional and trading conditions and they can, in turn, be used to examine whether accounting information is associated with and predicts systematic risk in different circumstances.

\section{Accounting Risk Variables}

Twelve accounting variables are selected for inclusion as potential explanators for the above market determined risk models. These variables are derived from both the 
theoretical model of accounting based systematic risk and past empirical research. They are defined below and classified into operating risk (7 variables), financing risk (2 variables) and growth risk (3 variables).

\section{Operating Risk}

1. Accounting Beta $\left(\beta_{\text {Accit }}\right)$ : the degree of co-variability of a firm's earnings and the earnings of the market and as per Elgers (1980) and Laveren et al. (1997). This is a non-market measure of systematic risk and is due to economy wide factors, as opposed to the unsystematic component that relates to other firm specific factors. The accounting beta was expressed in Bowman (1979) as:

$$
\beta_{A C C i}=\frac{\operatorname{Cov}\left(X_{i} X_{m}\right)}{\operatorname{Var}\left(X_{m}\right)}
$$

where $\beta_{A C C i}$ is the accounting beta, $X_{i}$ is accounting earnings for firm $i$, and $X_{m}$ is accounting earnings for the market portfolio. The Bowman study theorises that the higher the accounting beta, the higher the systematic risk of a given firm. Hence, a positive relationship is expected between the two and is demonstrated by Beaver, Kettler and Scholes (1979), Bildersee (1975), Elgers (1980), and Laveren et al., (1997). Empirically, the measure of accounting beta is defined as:

$$
\text { accbeta }=\frac{\sum_{t=1}^{T}\left(E_{t} / P_{t-1}-\left[E^{\prime} / P\right]\right)\left(M_{t}-M^{\prime}\right)}{\sum_{t=1}^{T}\left(M_{t}-M^{\prime}\right)\left(M_{t}-M^{\prime}\right)}
$$

where $E_{t}$ is earnings for ordinary shareholders for the period, $P_{t-1}$ is opening market value of common equity for the $t$ period, $\left(E^{\prime} / P\right)$ is average earnings scaled by opening market value, $M_{t}$ is average accounting earnings for all firms in the market in year $t$ and $M^{\prime}$ is average accounting earnings for all firms in the market in a sub period. ${ }^{\text {ix }}$ 2. Earnings Variance $\left(E V_{i t}\right)$ : the standard deviation in earnings over the T period interval (Beaver, Kettler and Scholes, 1970; Bildersee, 1975; Castagna and Matolcsy, 1978). 
3. Earnings Sign $\left(E S_{i t}\right)$ : a dichotomous dummy variable, where if earnings are determined to be negative in two or more of the periods in the $T$ period interval then the firm is defined as a negative earnings firm (denoted as a 0 ). If this is not the case then the firm is denoted a positive earnings firm (denoted with a 1) (Hayn, 1995).

4. Cash Flow $\left(C F_{i t}\right)$ : income available to common shareholders plus depreciation divided by beginning of the period market value of common equity (Ismail and Kim, 1989).

5. Dividend Payout Ratio $\left(D P R_{i t}\right)$ : a ratio of average $t$ period dividends to ordinary shareholders over the average $t$ period ordinary profit. The purpose of this is to eliminate the effect of low-income years from biasing the ratio (Beaver, Kettler and Scholes, 1970; Castagna and Matolcsy, 1978).

6. Operating Leverage $\left(O p L e v_{i t}\right)$ : the average $t$ period absolute ratio of operating profit before interest and tax to sales (Lev, 1974; Rosenberg and McKibben, 1973). This ratio is equivalent to the theoretical profit margin risk (Penman, 2001).

7. Liquidity $\left(L i q_{i t}\right)$ : the average $t$ period ratio of current assets to current liabilities equivalent to operating liability leverage risk (Beaver, Kettler and Scholes, 1970; Castagna and Matolcsy, 1978).

\section{Financing Risk}

8. Financial Leverage $\left(F L e v_{i t}\right)$ the average ratio of total liabilities to total assets over the $T$ period interval (Beaver, Kettler and Scholes, 1970; Castagna and Matolcsy, 1978).

9. Interest Coverage $\left(\operatorname{ICov}_{i t}\right)$ : Datastream provides the interest coverage data that is used in this study. ${ }^{\mathrm{x}}$ This is defined as profit plus total interest divided by total interest (where profit is pre-tax profit) averaged over the $T$ period interval (Rosenberg and Marathe, 1975; Bildersee, 1975).

\section{Growth Risk}

10. Growth $\left(G t h_{i t}\right)$ : the average log change in total assets over the period (Beaver, Kettler and Scholes, 1970; Castagna and Matolcsy, 1978).

11. Size $\left(\right.$ Size $\left._{i t}\right)$ : the average log of market value of equity (Ataise, 1985; Freeman, 1987). Size is hypothesised to be inversely related to growth with small firms more likely to grow at a faster rate. 
12. Market-to-book $\left(M r k t B k_{i t}\right)$ : the closing market value of the firm divided by the end of period book value, averaged over the $T$ period interval. The higher the marketto-book ratio the higher is the probability that unrecognised intangibles will contribute to future growth.

The descriptive statistics for the full data set are reported in Table 1. The OLS beta provides the highest estimate of risk (mean of 0.778) whilst the unlevered beta provides the lowest (mean of 0.631 ). The descriptive statistics also indicate that a wide range of firms have been sampled, including firms with high and low accounting betas, high growth and negative growth firms, and firms that are relatively highly and lowly geared (as measured by the financial and operating leverage variables). Hence, the results are reflective of a wide range of organisations in a variety of financial positions.

\section{Insert Table 1 Here}

\section{Multivariate Regression Model}

A multivariate regression is used to model the relationship between accounting variables and systematic risk. There are five models, each examining the association between the accounting variables and the five beta risk measures estimated over the period 1991 through 2000 . The models are defined as:

$$
\begin{gathered}
\beta_{\text {jit }}=\alpha_{i}+b_{1} \beta_{\text {accit }}+b_{2} \mathrm{EV}_{\text {it }}+b_{3} \mathrm{ES}_{\mathrm{it}}+\mathrm{b}_{4} \mathrm{CF}_{\mathrm{it}}+\mathrm{b}_{5} \mathrm{Gth}_{\mathrm{it}}+\mathrm{b}_{6} \text { Size }_{\mathrm{it}}+\mathrm{b}_{7} \mathrm{DPR}_{\mathrm{it}}+\mathrm{b}_{8} \mathrm{Liq}_{\mathrm{it}}+ \\
\mathrm{b}_{9} \text { Flev }_{\mathrm{it}}+\mathrm{b}_{10} \mathrm{Icov}_{\mathrm{it}}+\mathrm{b}_{11} \mathrm{OpLev}_{\mathrm{it}}+\mathrm{b}_{12} \mathrm{MrktBk}_{\mathrm{it}}+\varepsilon_{\mathrm{it}}
\end{gathered}
$$

where $j$ alternatively represents the $O L S, S W, V A S, U N L E V, G A R C H$ and the accounting variables are as defined above. Equation (9) is estimated over three intervals within the 10-year data set, two five-year (short term) periods (1991-1995 and 1996-2000) and one ten-year (long term) period.

Another important issue to consider is the different structure of operations between industries and the fact that this may influence the importance of different accounting variables. In order to test for such effects the data is split into two industry groupings, 
extractive and non-extractive industries ${ }^{\mathrm{xi}}$ and a dichotomous zero/one dummy variable is used in the regression analysis. This approach also increases the comparability of the results with the prior literature as some studies exclude extractive industries (eg. Castagna and Matolcsy, 1978).

The descriptive statis tics for the split sample are presented in Table 2 below and they illustrate some distinct differences between the two industry groups. A feature is the higher systematic risk measures; for example the means of the five measures are, on average, 0.283 higher for the extractive industry firms. Moreover, extractive industry firms have higher variance in their earnings, lower cash flows, and are smaller in size. They also have higher liquidity, lower leverage, and lower interest coverage, with similar levels of growth. Hence, there appears to be some divergence within the industry groupings and this suggests there may be some differences in the risk relevance of accounting information between them.

\section{Validation of the Regression Models}

A variety of statistical tests are conducted in order to assess the data set and the assumptions required for regression modelling. Normality plots of both the bivariate and the multivariate residuals are examined to assess the characteristics of the sample distributions for all models. Furthermore, Durbin-Watson statistics are examined to assess the possibility of correlation between the residuals. The possibility of an outlier significantly affecting the statistical estimates is examined using Cook distance tests, case wise diagnostics, ${ }^{\text {ii }}$ and visual inspection through scatter plots. In all cases the statistical results were within acceptable boundaries and hence presented no major problems.

Another potential problem is the existence of multicollinearity between the independent variables that may bias the estimates of the model variables. Multicollinearity is assessed using a condition index where a high condition index (higher than 30) indicates the existence of multicollinearity. ${ }^{x i i}$ In all models this test revealed no problems. ${ }^{\text {xiv }}$ Finally, in order to control for heteroskedasticity we applied White (1980) consistent covariance matrix estimators.

\section{Insert Table 2 About Here}




\section{$4 \quad$ Results}

\section{The Association Between Accounting Variables and the Beta Risk Measures}

Overall, the results indicate that the accounting variables possess significant levels of risk relevant information, explaining between $33-67 \%$ of the variation in the five measures of systematic risk (see table 3 ). ${ }^{\mathrm{xv}}$ As a visual aid the significant coefficients are shaded in Table 4. The GARCH model had the highest association with an $R^{2}$ of $67 \%$, indicating that accounting variables are able to pick up dynamic changes in the underlying risk environment. The GARCH model was followed by the unlevered and central tendency adjusted betas both on $62 \%$, the OLS beta on $60 \%$ and the thin trading beta on $33 \%$. Whilst the thin trading beta only captures $33 \%$ this is comparable with Rosenberg and McKibben (1973) who also found 33\% and Castagna and Matolcsy (1978) who found 45\%.

\section{$\underline{\text { Insert Tables } 3 \text { \& } 4 \text { About Here }}$}

Turning to the accounting variables, the operating risk variables perform consistently, with earnings variance and operating leverage statistically significant across all five models. Further, earnings sign and accounting beta are statistically significant in three and four of the systematic risk models, respectively. This suggests that accounting measures of operating risk contain highly relevant information for the estimation of systematic risk. Of the others, cash flow is significant in two models and dividend payout and liquidity are insignificant in all models.

In terms of the financing risk variables, there is little evidence of risk relevance with financial leverage insignificant in all models and interest coverage statistically significant in only one model (OLS Beta). Hence, there appears to be little risk relevant information contained in accounting measures of financing risk. This may be due to financial leverage being measured with accounting values based on historical cost rather than 'fair values', and which do not include other important items such as intangibles, off-balance sheet assets and liabilities, and contingencies. It may also be related to the Modiglianni and Miller hypothesis of the irrelevance of moderate levels of financial leverage. 
The results for the growth risk variables show that firm size is significant across all five models but growth and market-to-book are only significant in one model. This indicates that firm size captures most of the information regarding growth in the Australian market. Another observation is that the sign of the size variable is positive and inconsistent with past US research (increased size is associated with reduced risk) but consistent with prior Australian evidence (Castagna and Matolcsy, 1978). Explanations offered by Castagna and Matolcsy (1978) were a time specific effect and the taking on of more risk by larger Australian firms. Our results lend support to the latter explanation. Of further note is that dividends, liquidity and financial leverage are not significant in any model.

Comparing the results between the M-GARCH and OLS models, cash flow, growth and interest coverage are significant in the OLS, but not in the M-GARCH model. This shows that the estimation is sensitive to the type of risk being estimated but we surmise the M-GARCH model is the more appropriate model for a dynamic economic environment and this can be estimated using a more parsimonious accounting model. We also decomposed the data into two 5-year periods - 1991-1995 and 1996-2000 and rerun the above analysis to test the sensitivity of the estimation to the time period and economic activity (bear v's bull market). The results reinforced the pattern of significance in accounting variables and of particular note was the strong performance of firm size and operating leverage across both periods (significant in all 15 regressions).

In summary, the evidence presented here supports the notion of the strong relationship between operating risk (operating leverage and earnings variance) and size (as a surrogate for growth risk) in line with prior literature (Beaver, Kettler and Scholes, 1970; Lev, 1974; Castagna and Matolcsy, 1978). Points of difference, however, arise in several areas. First, the lack of evidence for the dividend payout ratio is not consistent with prior studies (Beaver, Kettler and Scholes, 1970; and Rosenberg and McKibben, 1973) but consistent with another study in a smaller market (Laveren et al., 1997).

In terms of the previous Australian study (Castagna and Matolcsy, 1978) the results are similar. Both studies (using the OLS results) agree on the statistical significance 
and sign of the growth, earnings sign, liquidity and firm size variables. Differences arise in the dividend payout ratio and financial leverage variables, which are not found to be significant in this study. The postulated relationship between systematic risk and earnings variance was not found in Castagna and Matolcsy (1978). The lack of risk relevance of dividend payout ratios may be due to a lack of reliance on internally generated capital in favour of external sources, together with the relative inflexibility of dividends over time (the sticky dividend theorem). In terms of risk relevance of earnings volatility, this may be a function of the increased frequency of loss reporting (and hence volatility) where a negative earnings stream affects risk in the sense that it increases the possibility of liquidation and downward adjustments in stock price. This in turn affects a firm's ability to attract funding and is indicative of earnings instability and, hence, is related to systematic risk (Hayn, 1995). Thus, it appears that the importance of financial risk may have decreased over time and the importance of operating variables, such as earnings volatility, increased.

\section{Industry Beta Results}

This section presents the results of the regressions when the sample is partitioned based on extractive and non-extractive industries. The motivation behind this is twofold; first to provide initial evidence of an industry effect in terms of the association of accounting risk variables with beta risk; and second to facilitate comparisons with prior studies that excluded extractive industries (e.g. Castagna and Matolcsy, 1978).

The results presented in Table 5 illustrate some differences in terms of the importance of the accounting variables when industry grouping is controlled. The dummy variables on size and liquidity are significant and positively related to risk for the extractive industries. Hence, high risk firms in the extractive industries appear to attempt to control for systematic risk by incorporating higher liquidity in their financial structure and, thus, the size and liquidity variables are found to be more relevant to the extractive industry group in this period. Further, the market-to-book value dummy in extractive industries is highly significant and negative. Thus, the higher the intangible value (or growth prospects) embedded in extractive industry firms then the lower is systematic risk. Taken together with the above results they 
show that there are not only country differences in the risk relevant attributes of accounting variables but also industry differences.

\section{Prediction of Risk}

A number of papers extend the accounting risk models to examine the predictive ability of accounting risk measures for systematic risk. To facilitate an assessment of the predictive ability of the accounting risk models, an out-of-sample forecast utilising a series of one year forecasting models is estimated to examine the short-term predictive ability of the accounting risk variables. These tests involve forecasting the M-GARCH average monthly beta over the next year using equation (9). ${ }^{\mathrm{xv}}$ To provide context and a basis of comparison to these results, three other forecasting techniques are also employed:

1. A naïve model, which assumes that the second period M-GARCH beta will be equal to the first period M-GARCH beta.

2. A market average beta, which assumes that the weighted average beta of the market is one, and therefore next period beta for all stocks will be one.

3. An industry average beta, which assumes the second period M-GARCH beta will be equal to the industry average previous M-GARCH period beta.

This is conducted where the initial 1991-1995 sub-sample is utilised as the estimation period to predict the 1996 period. This is then rolled forward one year to 1992-1996 and repeated, resulting in a pooled set of forecasts over five years ${ }^{\text {xvii }}$ with which to test the short-term predictive properties of accounting variables for systematic risk.

\section{Insert Table 5 About Here}

The forecasts are evaluated using a range of error statistics including the mean absolute error and the Theil inequality coefficient and its three components. The mean squared error compares the predicted betas with the actual betas and provides a measure of the accuracy of the forecast. This is defined as: 


$$
\text { Mean Absolute Error }=\sum_{t=T+1}^{T+h} \frac{\left|y_{t}-Y_{t}\right|}{(h+1)}
$$

where $y_{t}$ is the predicted beta for firm $i, Y_{t}$ is the actual beta for firm $i$ and $h$ is the number of predictions. It is also important to note that $y_{i}$ and $Y_{i}$ represent the actual and forecasted values of the different betas, and hence the interpretation of the results depends on the scale of the dependent variable. Consequently, they are used as relative measures of forecast error, where the smaller the error, the more accurate the forecast.

The Theil inequality coefficient is a scale invariant measure of forecast performance and always lies between zero and one, with zero indicating a perfect forecast. This overcomes potential comparison and interpretation problems caused by the scale variance of the mean squared and absolute error terms. The Theil inequality coefficient is computed as:

$$
\frac{\sqrt{\sum_{t=T+1}^{T+h} \frac{\left(y_{t}-Y_{t}\right)^{2}}{(h+1)}}}{\sqrt{\sum_{t=T+1}^{T+h} \frac{y_{t}^{2}}{(h+1)}}+\sqrt{\sum_{t=T+1}^{T+h} \frac{Y_{t}^{2}}{(h+1)}}}
$$

This can be decomposed into three components:

$$
\sum \frac{\left(y_{t}-Y_{t}\right)^{2}}{h}=\left(\left(\sum \frac{y_{t}}{h}\right)-\bar{y}\right)^{2}+\left(s_{y}-S_{y}\right)^{2}+2(1-r) s_{y} s_{Y}
$$

where $\left(\sum \frac{y_{t}}{h}\right), \bar{y}, s_{y}, S_{y}$ are the means and standard deviations of $y_{t}$ and $Y_{t}$, and $r$ is the correlation between $y_{t}$ and $Y_{t}$. The three proportions of the forecast error are defined as; (1) the bias proportion, measuring how far the mean of the forecast is from the mean of the actual series; (2) the variance proportion, measuring how far the variation of the forecast is from the variance of the actual series; and (3) the covariance 
proportion measuring the remaining unsystematic forecasting errors. These are defined as:

$$
\begin{aligned}
& \text { Bias proportion }=\frac{\left(\left(\sum \frac{y_{t}}{h}\right)-\bar{y}\right)^{2}}{\frac{\sum\left(y_{t}-Y_{t}\right)^{2}}{h}} \\
& \text { Variance Proportion }=\frac{\left(s_{y}-S_{y}\right)^{2}}{\frac{\sum\left(y_{t}-Y_{t}\right)^{2}}{h}} \\
& \text { Covariance Proportion }=\frac{2(1-r) s_{y} S_{y}}{\frac{\sum\left(y_{t}-Y_{t}\right)^{2}}{h}}
\end{aligned}
$$

The differences between the forecasting error statistics of the accounting variable based forecasting model and the other forecasting techniques are tested using independent t-tests and Mann-Whitney $\mathrm{U}$ tests. The results are summarised in table 6.

Overall, the results show a superiority of the accounting based risk model when compared to the naïve and market based models as forecasters of future risk. In terms of the accounting and industry models, in three of the five periods the industry model outperforms the accounting model in raw error statistics. However, once we decompose the Theil coefficients, the indication is that the accounting model is superior in terms of variance and in three of the five years in the bias proportion. The 5-year average statistics show a similar story. These conclusions also support prior research that accounting measures improve on the forecasting ability of market risk measures (Beaver, Kettler and Scholes, 1970; Castagna and Matolcsy, 1978).

\section{Insert Table 6 About Here}

\section{Long Term Relationship Between Accounting Variables and Risk}

Having found evidence of both a contemporaneous association between and predictive ability of accounting variables for estimates of systematic risk, another research question relates to the long-term relationship between these concepts. This is 
particularly interesting in the context of both the professional (Rimerman, 1990; Jenkins, 1994) and academic literature (Collins, Maydew and Weiss, 1997; Francis and Schipper, 1999; Lev and Zarowin, 1999; Brown, Lo and Lys, 1999) that suggest the value relevance of accounting information has declined over time.

Utilising a sample of 2467 firm year observations over the 1973-2001 period $^{\mathrm{xviii}}$ we examine the long-term relationship between market risk and accounting information using the following model:

$$
\begin{aligned}
& \beta_{i t}=\alpha_{1}+\alpha_{2} \text { Accbeta }_{i t}+\alpha_{3} E V_{i t}+\alpha_{2} \text { ES }_{i t}+\alpha_{4} \text { Grth }_{i t}+ \\
& \alpha_{5} \text { Flev }_{i t}+\alpha_{6} \text { Size }_{i t}+\alpha_{7} \text { Oplev }_{i t}+\alpha_{8} \text { Liq }_{i t}
\end{aligned}
$$

where $\beta_{i t}$ is estimated also using a constant correlation multivariate GARCH (MGARCH) model with significant accounting risk variables drawn from our previous results. This is implemented in a similar fashion to an association test with a five year moving estimation period for the beta calculation which is regressed on a yearly basis against the accounting data of the final year of the estimation period. For example, the five-year estimation period of 1973-1977 is used to estimate the GARCH beta (the dependant variable) while the accounting variables (the independent variables) are those for the 1977 year. A time trend regression is estimated using the $R^{2}$ of the yearly regressions to estimate the time trend in the risk relevance of the accounting variables as follows:

$$
\overline{R_{t}^{2}}=\phi_{0}+\phi_{1} T I M E+\varepsilon_{i t}
$$

The results presented in Table 7 provide evidence that supports a continuously strong relationship of the risk relevance of accounting information over time with an $R^{2}$ that averages 41 percent over the period 1977-2001. More importantly, the evidence shows that the coefficient on time is not significant indicating a long-term association between accounting risk variables and $\mathrm{M}-\mathrm{GARCH}$ beta over the period. This evidence supports the argument that the risk relevance of accounting information has not deteriorated over time whilst other researchers have found that the value relevance of accounting information for prices has deteriorated. Perhaps the emphasis has 
shifted from a valuation perspective to more a risk perspective as markets become more volatile.

\section{Insert Table 7 Here}

\section{$5 \quad$ Summary and Conclusions}

The objective of this paper was to examine the association between accounting information and various measures of systematic risk. To achieve this five measures of systematic risk and twelve accounting risk related variables were selected based upon theoretical and empirical research. The results indicate that there is a strong association between the accounting variables and systematic risk with up to $67 \%$ of the cross sectional variance in the systematic risk measures explained by the accounting variables in the MGARCH model. The accounting variables; earnings variance, firm size and operating leverage consistently exhibit strong associations across all risk models, whilst other variables (accounting beta, earnings sign and growth) have weaker associations. This confirms that accounting data that captures operating risk and growth risk are important, but that accounting variables that proxy for financing risk may be less so and has declined in importance over time. There are also industry effects with extractive industries having a significantly different association with systematic risk measures with regard to size, liquidity and market-tobook compared to non-extractive industries. Furthermore, the accounting variable risk model is a superior model for predicting forward time-varying systematic risk (M-GARCH) suggesting that the accounting risk variables also contain useful information about future risk. Finally, the risk relevance of accounting information has remained stable over time with a long-term stable relationship established over the 1973-2001 period.

This study opens up several avenues for further research. These include: (1) further investigation of the impact of industry membership on both the association of the accounting variables to risk and the prediction thereof; (2) the impact of different economic and country specific conditions, particularly with regard to any momentum effects and whether the market is in an upward or a downward trend; (3) whether any trading strategies can be developed from both the beta estimation methods and the 
accounting variable models; and (4) the adoption of the accounting risk models for private/non-listed entities.

\footnotetext{
${ }^{\mathrm{i}}$ For example, in 2001 there were approximately 7,700 firms listed on the US stock exchanges (NYSE (2800), NASDAQ (4100), AMEX (800)) and 5,820,000 unlisted firms - less than 1 percent of firms. Sources: Office of Advocacy, US Small Business Administration and the various exchanges.

${ }^{\mathrm{ii}}$ Examples of non-accounting variables include share price, stock exchange and share turnover.

${ }^{\text {iii }}$ These were accounting beta, financial leverage, earnings variability, dividend payout, growth, size, current ratio, operating leverage, trading volume, cut in dividends, plant/total assets, log share price, and earnings/price.

${ }^{\text {iv }}$ The accounting variables examined were cash flow, asset growth, financial leverage, earnings variability, dividend payout, asset size, accounting beta, current ratio and capital intensity.

${ }^{\mathrm{v}} \mathrm{Such}$ as derivative positions, trading volume, and stock price volatility.

${ }^{\mathrm{vi}}$ The accounting variables examined were financial leverage, profitability, growth, liquidity, dividend payout, firm size, earnings variability and interest coverage.

${ }^{\text {vii }}$ Financial firms are also excluded from the sample.

${ }^{\text {viii }}$ The initial sample was 145 firms which the Datastream database indicated had the ten years of accounting and market information required, however, firms were deleted for having incomplete accounting data (8), incomplete market data (6), and for being finance/insurance firms (2) leaving a final sample of 129.

ix Where earnings are scaled by opening market value and the market earnings is proxied by the full sample of firms.

${ }^{\mathrm{x}}$ Datastream line item 1503

${ }^{x i}$ Extractive industries includes mining and mining exploration firms as per the Datastream industry codes with all others in the non-extractive industries group.

${ }^{x i i}$ This tests for residuals that are more than a set (in this case 3) standard deviations away from the mean.

xiii The condition index is the square root of the ratio of the largest to the smallest characteristic of the root of $X^{\prime} X^{\prime}$.

${ }^{\text {xiv }}$ The highest condition index being 20.5, with most being below 12 . Variance inflation factors were also examined and these showed there were no problems.

${ }^{x v}$ Table 3 presents results for the ten year pooled beta period. Results for the two shorter intervals (1991-1995 and 1996-2000) are broadly similar and hence are not reported separately.

${ }^{x v i}$ Given the results presented in the prior sections that the M-GARCH beta illustrates the superior association with the accounting risk variables.

xvii The predicted years are 1996-2000.

${ }^{x v i i i}$ Data is collected from Datastream and Microfiche for all firms with a minimum of five years continuous data available (to facilitate the beta calculation) with all required accounting and market variables available.
} 


\section{References}

Alexander, G.J. and N.L. Chervany, 1980, On the Estimation of Stability of Beta, Journal of Financial and Quantitative Analysis, March, 123-137.

Atiase, R.K., 1985, Predisclosure Information, Firm Capitalisation, and Security Price Behaviour around Earnings Announcements, Journal of Accounting Research, 23 (1), 21-36.

Beaver, W., Kettler, P. and M Scholes, 1970, The Association between MarketDetermine and Accounting-Determined Risk Measures, The Accounting Review, October, 654-682.

Beaver, W. and J. Manegold, 1975, The Association between Market-Determined and Accounting Determined Measures of Systematic Risk: Some Further Evidence, Journal of Financial and Quantitative Analysis, 231-284.

Bildersee, J.S., 1975, The Association Between a Market Determined Measure of Risk and Alternative Measures of Risk, The Accounting Review, January, 81-89.

Bollerslev, T., 1990, Modelling the Coherence in Short Run Nominal Exchange Rates: A Multivariate Generalised ARCH Model, Review of Economics and Statistics, 72, 498-505.

Bowman, R.G., 1979, The Theoretical Relationship Between Systematic Risk and Financial Accounting Variables, The Journal of Finance, 617-630.

Brown, P.D. and Lo, K. and T. Lys, 1999, Use of R-Squared in Accounting Research: Measuring Changing Value Relevance over the Last Four Decades, Journal of Accounting and Economics, 28, 83-115.

Castagna, A.D. and Z.P. Matolcsy, 1978, The Relationship between Accounting Variables and Systematic Risk and the Prediction of Systematic Risk, Australian Journal of Management, 113-126.

Cheon, Y., Duchac, J. and S. Goldberg, 1996, The Effect of Derivate Usage on Risk, Working Paper, Grand Valley State University.

Collins, D., Maydew, E. and I. Weiss, 1997, Changes in the Value-Relevance of Earnings and Book Values Over the Past Forty Years, Journal of Accounting and Economics, 24, 39-67.

Dimson, E., 1979, "Risk Measurement when Shares are Subject to Infrequent Trading", Journal of Financial Economics, 7, pp. 197-226.

Elgers, P.T., 1980, Accounting Based Risk Prediction, The Accounting Review, 15, 3, 389-408. 
Faff, R.W., Hodgson, A. and S. Saudagaran, 2001, "International Cross-Listings Towards more Liquid Markets: The Impact on Domestic Firms", Working Paper, Griffith University.

Francis, J. and K. Shipper, 1999, Have Financial Statements Lost Their Relevance?, Journal of Accounting Research, Autumn, 319-352.

Freeman, R.N., 1987, The Association Between Accounting Earnings and Security Returns for Large and Small Firms, Journal of Accounting and Economics, 1987, 9, 195-228.

Hayn, C., 1995, "The Information Content of Losses", Journal of Accounting and Economics, 20, pp. 125-153.

Hill, N.C. and B.K. Stone, 1980, Accounting Betas, Systematic Operation Risk, and Financial Leverage: A risk-Composition approach to the Determinants of Systematic Risk, Journal of Financial and Quantitative Analysis, 15, 594-638.

Ismail, B.E. and M.K. Kim, 1998, An Accounting Analysis of the Risk-Return Relationship in Bull and Bear Markets, Review of Financial Economics, Spring, 173182.

Ismail, B.E. and M.K. Kim, 1989, On the Association of Cash Flow Variables with Market Risk: Further Evidence, The Accounting Review, January, 125-136.

Jenkins, E., 1994 A Information Highway in Need of capital Improvements, Journal of Accountancy, May, 77-82.

Laveren, E., Durinck, E., De Ceuster, M. and N. Lybaert, 1996, Beta Estimation and Unlevering, Working Paper, Antwerpen.

Laveren, E., Durinck, E., De Ceuster, M. and N. Lybaert, 1997, Can Accounting Variables Explain and Beta?, Working Paper, Antwerpen.

Lev, B., 1974, On the Association between Operating Leverage and Risk, Journal of Financial and Quantitative Analysis, 9, 627-641.

Lev, B and S. Kunitzky, 1974, On the Association Between Smoothing Measure and the Risk of Common Stocks, The Accounting Review, April, 259-270.

Lev, B. and P. Zarowin, 1999, The Boundaries of Financial Reporting and How to Extend them, Journal of Accounting Research, 37, 353-385.

Lintner, J., 1965, The Valuation of Risk Assets and the Selection of Risky Investments in Stock Portfolios and Capital Budgets, The Review of Economics and Statistics, 47, 13-37.

McAnally, M., 1996, Banks, Risk, and FAS No.105 Disclosures, Journal of Accounting, Auditing, and Finance, Summer, 453-496. 
Penman, S.H., 2001, Financial Statements Analysis and Security Valuation, McGraw Hill.

Rosenberg, B. and V. Marathe, 1975, The Prediction of Investment Risk: Systematic and Residual Risk, Berkeley Working Paper Series.

Rosenberg, B. and W. McKibben, 1973, The Prediction of Systematic and Specific Risk in Common Stocks, Journal of Financial and Quantitative Analysis, March, 317333.

Ryan, S., 1997, A Survey of Research Relating Accounting Numbers to Systematic Equity Risk, with Implications for Risk Disclosure Policy and Future Research', Accounting Horizons, 11, 82-95.

Scholes, M., 1996, Global Finance Markets, Derivative Securities, and Systematic Risks, Journal of Risk and Uncertainty, May, 271-286.

Scholes, M. and J. Williams, 1977, Estimating Betas from Non-Synchronous Data, Journal of Financial Economics, 5, 309-327.

Sharpe, W., 1964, Capital Asset Prices: A Theory of Market Equilibrium, Journal of Finance, 19, 425-442.

Vasicek, O., 1973, A Note on Using Cross-Sectional and Time-Series Beta Adjustment Techniques, Journal of Business Finance and Accounting, 14, 1233-1239. 


\section{Figure 1}

The Relationship between Accounting Variables and Systematic Risk

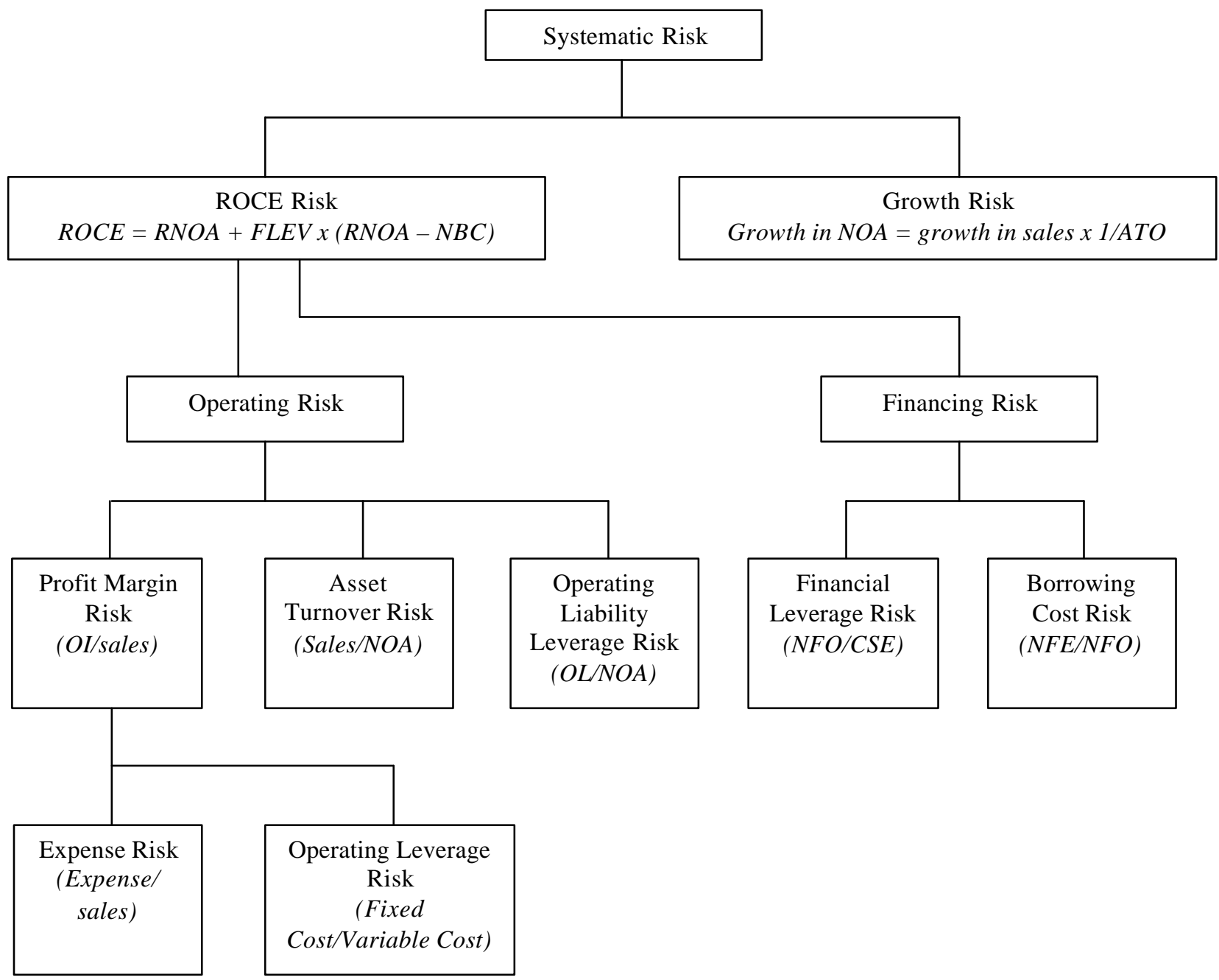

Where ROCE is rate of return on common equity, RNOZ is rate of return on net operating assets, FLEV is financial leverage, NBC is net borrowing cost, OI is operating income, OL is operating liabilities, NOA is net operating assets, ATO is asset turnover, NFE is net financial expense, NFO is net financial obligations and CSE is common shareholders equity. Source: Penman (2001) 


\section{Table 1}

\section{Descriptive Statistics for the Pooled Data Set}

\begin{tabular}{|c|c|c|c|c|c|}
\hline Variable & Mean & $\begin{array}{r}25^{\text {th }} \\
\text { Percentile }\end{array}$ & $\begin{array}{r}50^{\text {th }} \\
\text { Percentile }\end{array}$ & $\begin{array}{r}75^{\text {th }} \\
\text { Percentile }\end{array}$ & $\begin{array}{r}\text { Expected } \\
\text { Sign }\end{array}$ \\
\hline \multicolumn{6}{|l|}{ Betas } \\
\hline$\beta_{\mathrm{OLS}}$ & .778 & .417 & .772 & 1.063 & $\mathrm{~N} / \mathrm{R}$ \\
\hline$\beta_{\mathrm{SW}}$ & .643 & .219 & .580 & .995 & $\mathrm{~N} / \mathrm{R}$ \\
\hline$\beta_{\mathrm{VAS}}$ & .744 & .507 & .768 & .969 & $\mathrm{~N} / \mathrm{R}$ \\
\hline$\beta_{\text {UNLEV }}$ & .631 & .350 & .611 & .847 & $\mathrm{~N} / \mathrm{R}$ \\
\hline$\beta_{\mathrm{GARCH}}$ & .748 & .363 & .665 & 1.022 & $\mathrm{~N} / \mathrm{R}$ \\
\hline \multicolumn{6}{|c|}{ Operating Risk Variables } \\
\hline AccBeta & .241 & -.387 & .027 & .375 & + \\
\hline $\mathrm{EV}$ & .127 & .018 & .035 & .096 & + \\
\hline $\mathrm{CF}$ & .083 & .070 & .113 & .149 & - \\
\hline DPR & .524 & .000 & .509 & .741 & - \\
\hline OpLev & .083 & .007 & .103 & .215 & + \\
\hline Liq & 1.843 & 1.149 & 1.547 & 2.244 & - \\
\hline \multicolumn{6}{|c|}{ Financing Risk Variables } \\
\hline Flev & 2.755 & .495 & 2.612 & 4.242 & + \\
\hline Icov & 3.152 & .000 & 3.390 & 8.750 & - \\
\hline \multicolumn{6}{|c|}{ Growth Risk Variables } \\
\hline Gth & .036 & -.013 & .057 & .129 & + \\
\hline Size & .487 & .314 & .495 & .660 & - \\
\hline MrktBk & 1.866 & .990 & 1.730 & 3.005 & - \\
\hline
\end{tabular}

The above table presents descriptive statistics for the full 10-year (1991-2000) data set. 
Table 2

\section{Descriptive Statistics for the Industry Sub Samples}

\begin{tabular}{|c|c|c|c|c|c|c|c|c|}
\hline \multirow[b]{2}{*}{$\begin{array}{l}\text { Variabl } \\
\text { e }\end{array}$} & \multicolumn{4}{|c|}{ Non-Extractive Industries } & \multicolumn{4}{|c|}{ Extractive Industries } \\
\hline & Mean & $25^{\text {th }} \%$ & $\mathbf{5 0}^{\text {th }} \%$ & $\begin{array}{r}\mathbf{7 5}^{\text {th }} \\
\%\end{array}$ & Mean & $25^{\text {th }} \%$ & $50^{\text {th }} \%$ & $75^{\text {th }} \%$ \\
\hline \multicolumn{9}{|l|}{ Betas } \\
\hline$\beta_{\mathrm{OLS}}$ & .686 & .361 & .624 & .922 & .956 & .516 & .974 & 1.386 \\
\hline$\beta_{\mathrm{SW}}$ & .519 & .149 & .537 & .799 & .957 & .395 & .840 & 1.577 \\
\hline$\beta_{\mathrm{VAS}}$ & .666 & .445 & .650 & .896 & .901 & .624 & .908 & 1.217 \\
\hline$\beta_{\text {UNLEV }}$ & .564 & .295 & .527 & .737 & .805 & .453 & .776 & 1.158 \\
\hline$\beta_{\mathrm{GARCH}}$ & .669 & .335 & .596 & .913 & .902 & .299 & .912 & 1.445 \\
\hline \multicolumn{9}{|c|}{ Operating Risk Variables } \\
\hline AccBeta & .611 & -.034 & .042 & .398 & .159 & -.127 & .015 & .219 \\
\hline $\mathrm{EV}$ & .084 & .016 & .029 & .061 & .165 & .021 & .044 & .112 \\
\hline $\mathrm{CF}$ & .126 & .094 & .124 & .153 & .031 & -.055 & .081 & .129 \\
\hline DPR & .606 & .336 & .605 & .776 & .378 & .000 & .060 & .635 \\
\hline OpLev & .469 & .051 & .083 & .136 & 1.532 & .107 & .215 & .423 \\
\hline Liq & 1.774 & 1.171 & 1.497 & 1.975 & 4.537 & 1.103 & 1.739 & 3.286 \\
\hline \multicolumn{9}{|c|}{ Financing Risk Variables } \\
\hline Flev & 3.364 & 1.621 & 3.193 & 4.494 & 1.855 & .023 & 1.201 & 3.600 \\
\hline Icov & 1.986 & 1.943 & 4.290 & 9.547 & 1.238 & -2.770 & 1.200 & 7.180 \\
\hline \multicolumn{9}{|c|}{ Growth Risk Variables } \\
\hline Gth & .045 & -.011 & .052 & .121 & .041 & .015 & .075 & .180 \\
\hline Size & .520 & .371 & .512 & .669 & .465 & .258 & .456 & .646 \\
\hline MrktBk & 1.925 & .993 & 1.655 & 2.640 & 1.804 & .980 & 1.890 & 3.840 \\
\hline
\end{tabular}

The above table presents descriptive statistics for the 10-year (1991-2000) data set when split into two industry groups. The non-extractive industry has 75 firms, whilst the extractive industry group has 54 firms. 
Table 3

The Association Betwe en Various Measures of Systematic Risk and Theoretical Accounting Risk Variables

\begin{tabular}{|c|c|c|c|c|c|}
\hline Variable & $\mathbf{B}_{\mathrm{OLS}}$ & $\mathbf{B}_{\mathrm{SW}}$ & $\mathbf{B}_{\text {VAS }}$ & $\mathbf{B}_{\text {UNLEV }}$ & $\mathbf{B}_{\text {GARCH }}$ \\
\hline$\alpha_{i t}$ & -0.168 & -0.484 & $0.263^{n}$ & 0.098 & -0.220 \\
\hline \multicolumn{6}{|c|}{ Operating Risk Variables } \\
\hline AccBeta & $0.364^{* *}$ & 0.129 & -0.133 & $0.282^{* *}$ & $0.270^{* *}$ \\
\hline EV & $1.247^{* * *}$ & $2.363^{* * *}$ & $0.642^{* *}$ & $0.980^{* * *}$ & $1.131^{* * *}$ \\
\hline $\mathrm{ES}$ & $0.391^{* * *}$ & -0.032 & $-0.232^{* * *}$ & $-0.314^{* * *}$ & $-0.339^{* * *}$ \\
\hline $\mathrm{CF}$ & $-0.677^{* *}$ & -0.249 & -0.218 & $-0.609^{* *}$ & -0.116 \\
\hline DPR & 0.033 & -0.580 & 0.024 & -0.043 & -0.465 \\
\hline OpLev & $1.979^{* * *}$ & $6.103^{* *}$ & $1.022^{* * *}$ & $1.906^{* * *}$ & $1.506^{* * *}$ \\
\hline Liq & $-0.959^{*}$ & -0.256 & -0.041 & -0.112 & 0.604 \\
\hline \multicolumn{6}{|c|}{ Financing Risk Variables } \\
\hline Flev & 0.103 & -0.310 & 0.052 & 0.203 & 0.167 \\
\hline Icov & $0.235^{* * *}$ & 0.060 & -0.013 & 0.079 & 0.071 \\
\hline \multicolumn{6}{|c|}{ Growth Risk Variables } \\
\hline Gth & $0.755^{* *}$ & 0.522 & 0.299 & 0.448 & $0.577^{*}$ \\
\hline Size & $1.601^{* * *}$ & $1.488^{* * *}$ & $1.046^{* * *}$ & $1.483^{* * *}$ & $1.588^{* * *}$ \\
\hline MrktBk & -0.076 & $0.442^{* *}$ & 0.028 & $-0.716^{* * *}$ & 0.119 \\
\hline$\overline{A d j} R^{2}$ & 0.60 & 0.33 & 0.62 & 0.62 & 0.67 \\
\hline
\end{tabular}

This table presents regression coefficients for the 10-year period (1991-2000) using the following model:

$$
\begin{aligned}
& \beta j_{i t}=a_{i}+b_{1} \beta_{a c c i t}+b 2 E V_{i t}+b_{3} E_{i t}+b_{4} C F_{i t}+b_{5} G_{h} h_{i t}+b_{6} \text { Size }_{i t}+b_{7} D R_{i t}+b_{8} L_{i q} \\
& +\mathrm{b}_{9} \text { Flev }_{\text {it }}+\mathrm{b}_{10} \mathrm{Icov}_{\mathrm{it}}+\mathrm{b}_{11} \mathrm{OpLev}_{\mathrm{it}}+\mathrm{b}_{12} \mathrm{MrktBk}_{\mathrm{it}}+\mathrm{e}_{\mathrm{it}}
\end{aligned}
$$

where $\mathrm{j}$ is OLS, SW, VAS, UNLEV, and GARCH. ${ }^{*}$ indicates significance at the $10 \%$ level, ${ }^{* *}$ indicates significance at the $5 \%$ level, and ${ }^{* * *}$ indicates significance at the $1 \%$ level 
Table 4

Summary Statistics: Accounting Variables as Estimators of Systematic Risk

\begin{tabular}{cccccc}
\multicolumn{1}{c}{ Variable } & $\boldsymbol{B}_{\text {OLS }}$ & $\mathbf{B}_{\text {SW }}$ & $\boldsymbol{B}_{\text {VAS }}$ & $\boldsymbol{B}_{\text {UNLEV }}$ & B $_{\text {GARCH }}$ \\
\hline Panel A: Explanatory Power & Pow & & & & \\
Adj R $^{2}$ & .60 & .33 & .62 & .62 & .67
\end{tabular}

Panel B: Significant Accounting Variables Operating Risk Variables

AccBeta

EV

ES

$\mathrm{CF}$

DPR

OpLev

Liq

Financing Risk Variables

\begin{tabular}{|l|l|l|l|l|}
\hline & & & & \\
\hline & & & & \\
\hline & & & & \\
\hline & & & & \\
\hline & & & & \\
\hline & & & & \\
\hline & & & & \\
\hline
\end{tabular}

Flev

Icov

Growth Risk Variables

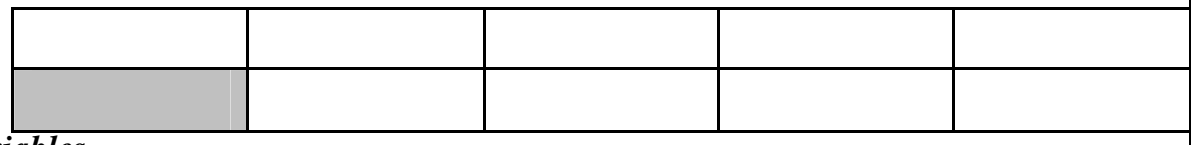

Gth

Size

MrktBk

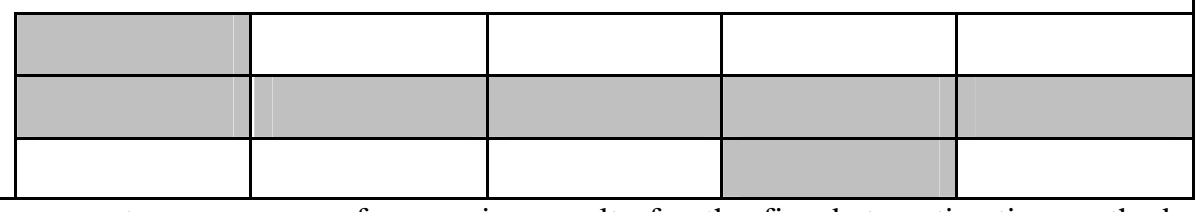

This table visually presents a summary of regression results for the five beta estimation methods examined. Panel A presents the explanatory power (as measured by the $\mathrm{R}^{2}$ ) of each model and panel $\mathrm{B}$ presents the accounting variables that are statistical associated with the different betas. A shaded box represents statistical significance at the $10 \%$ level or better. 


\section{Table 5}

The Association Between Various Measures of Systematic Risk and Accounting Risk Variables - The Impact of Industry

\begin{tabular}{|c|c|c|c|c|c|c|c|c|c|c|c|c|c|c|}
\hline Model & $\alpha_{i}$ & $\begin{array}{c}d_{1} \text { Acc } \\
\text { Beta } \\
\end{array}$ & $\mathrm{d}_{2} \mathrm{EV}$ & $d_{3} E S$ & $\mathrm{~d}_{4} \mathrm{CF}$ & d5Gth & $d_{6}$ Size & $\begin{array}{l}d_{7} D P R \\
\end{array}$ & $\mathrm{~d}_{8} \mathrm{Liq}$ & $\begin{array}{l}d_{9} \text { FLev } \\
\text { nat }\end{array}$ & $\mathrm{d}_{10} \mathrm{ICov}$ & $\begin{array}{c}d_{11} O P \\
\text { Lev }\end{array}$ & $\begin{array}{c}\mathrm{d}_{12} \mathrm{Mrkt} \\
\mathrm{Bk} \\
\end{array}$ & $\operatorname{Adj~} r^{2}$ \\
\hline \multicolumn{15}{|c|}{ Sample: $1991-2000$} \\
\hline$\beta_{\mathrm{OLS}}$ & 0.001 & 1.070 & 1.542 & 0.167 & -0.335 & -0.914 & $1.227^{* *}$ & $-3.023^{*}$ & $3.043^{\text {** }}$ & -0.306 & 0.092 & 0.992 & $-1.153^{* * * *}$ & 0.59 \\
\hline$\beta_{\mathrm{SW}}$ & 0.228 & -1.833 & $5.879^{*}$ & $0.723^{*}$ & 0.725 & -0.193 & 0.635 & -0.637 & 1.003 & $-1.480^{* * *}$ & 0.033 & -1.189 & $-0.785^{* * *}$ & 0.44 \\
\hline$\beta_{\mathrm{VAS}}$ & 0.207 & 0.665 & 0.952 & 0.106 & -0.306 & -0.406 & $0.713^{* *}$ & $-1.676^{*}$ & $1.667^{*}$ & -0.198 & 0.108 & 0.638 & $-0.697^{* * *}$ & 0.60 \\
\hline$\beta_{\text {UNLEV }}$ & -0.067 & 0.414 & 1.475 & 0.074 & -0.286 & -0.298 & $1.391^{* * * *}$ & $-3.411^{* * *}$ & $3.129^{* * *}$ & -0.470 & 0.177 & -1.949 & $-0.819^{* * *}$ & 0.65 \\
\hline$B_{\mathrm{GARCH}}$ & 0.023 & 0.984 & 0.893 & 0.108 & -0.427 & -0.833 & $0.807^{*}$ & $-2.547^{*}$ & $2.808^{* *}$ & -0.000 & 0.048 & 0.527 & $-1.112^{* * *}$ & 0.64 \\
\hline
\end{tabular}

This table presents summary regression results for the five beta estimation methods were industry membership is controlled for using a dichotomous dummy variable coded 0 for a non-extractive industries entity and 1 for an extractive industries entity. The above results are the coefficients on the industry dummies for the following equation:

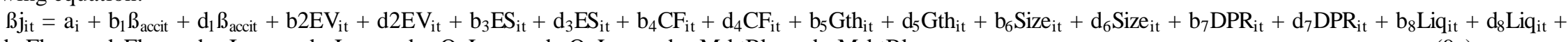
$\mathrm{b}_{9} \mathrm{Flev}_{\text {it }}+\mathrm{d}_{9} \mathrm{Flev}_{\text {it }}+\mathrm{b}_{10} \mathrm{Icov}_{\mathrm{it}}+\mathrm{d}_{10} \mathrm{Icov}_{\mathrm{it}}+\mathrm{b}_{11} \mathrm{OpLev}_{\mathrm{it}}+\mathrm{d}_{11} \mathrm{OpLev}_{\mathrm{it}}+\mathrm{b}_{12} \mathrm{MrktBk}_{\mathrm{it}}+\mathrm{d}_{12} \mathrm{MrktBk}_{\mathrm{it}}+\mathrm{e}_{\mathrm{it}}$

(9a)

where $\mathrm{j}$ is OLS, SW, VAS, UNLEV, and GARCH. ${ }^{*}$ indicates significance at the $10 \%$ level, ${ }^{* *}$ indicates significance at the $5 \%$ level, ${ }^{* * *}$ indicates significance at the $1 \%$ level. 
Table 6

Predictive Ability of Accounting Risk Va riables for the M-GARCH Beta:

Short Term Forecasting Results

\begin{tabular}{|c|c|c|c|c|c|}
\hline Model & $\begin{array}{l}\text { Mean Abs } \\
\text { Error }\end{array}$ & $\begin{array}{l}\text { Theil } \\
\text { Inequality } \\
\text { Coefficient }\end{array}$ & $\begin{array}{l}\text { Bias } \\
\text { Proportion }\end{array}$ & $\begin{array}{l}\text { Variance } \\
\text { Proportion }\end{array}$ & $\begin{array}{l}\text { Covariance } \\
\text { Proportion }\end{array}$ \\
\hline \multicolumn{6}{|c|}{1996 Forecast } \\
\hline Accounting & .249 & .209 & .001 & .009 & .989 \\
\hline Naïve & $.483^{* * *}$ & .415 & .009 & .020 & .969 \\
\hline Market & $.419^{* * *}$ & .285 & .357 & .642 & .000 \\
\hline Industry & $.349^{* * *}$ & .299 & .052 & .258 & .689 \\
\hline \multicolumn{6}{|c|}{1997 Forecast } \\
\hline Accounting & .312 & .245 & .011 & .049 & .938 \\
\hline Naïve & $.451^{* * * *}$ & .374 & .007 & .085 & .907 \\
\hline Market & $.368^{*}$ & .244 & .393 & .606 & .000 \\
\hline Industry & .248 & .203 & .001 & .464 & .534 \\
\hline \multicolumn{6}{|c|}{1998 Forecast } \\
\hline Accounting & .331 & .344 & .001 & .000 & .999 \\
\hline Naïve & $.469^{* * *}$ & .375 & .007 & .006 & .986 \\
\hline Market & $.444^{* *}$ & .322 & .238 & .762 & .000 \\
\hline Industry & .324 & .326 & .004 & .575 & .421 \\
\hline \multicolumn{6}{|c|}{1999 Forecast } \\
\hline Accounting & .313 & .271 & .060 & .274 & .664 \\
\hline Naïve & $.463^{* * *}$ & .371 & .004 & .061 & .934 \\
\hline Market & $.385^{* * *}$ & .276 & .518 & .481 & .000 \\
\hline Industry & $.272^{*}$ & .229 & .077 & .385 & .537 \\
\hline \multicolumn{6}{|c|}{2000 Forecast } \\
\hline Accounting & .323 & .220 & .027 & .037 & .935 \\
\hline Naïve & $.531^{* * *}$ & .376 & .020 & .036 & .942 \\
\hline Market & $.373^{* * *}$ & .261 & .126 & .873 & .000 \\
\hline Industry & $.326^{*}$ & .295 & .025 & .486 & .488 \\
\hline \multicolumn{6}{|c|}{ Average Prediction Performance } \\
\hline Accounting & .305 & .257 & .020 & .073 & .904 \\
\hline Naïve & .479 & .382 & .009 & .041 & .947 \\
\hline Market & .398 & .277 & .326 & .672 & .000 \\
\hline Industry & .304 & .275 & .032 & .434 & .533 \\
\hline
\end{tabular}

This table presents the forecast error statistics for an out-of-sample next period forecast where the estimation period is the five years preceding the forecast year. The estimation equation for the accounting prediction model is defined as:

$$
\begin{aligned}
& \beta_{\text {Garchit }}=a_{i}+b_{1} \beta_{\text {accit }}+b 2 E_{\text {it }}+b_{3} E_{i t}+b_{4} C F_{i t}+b_{5} G_{t h}+b_{6} S_{i z e}+b_{7} D_{i t} R_{i t}
\end{aligned}
$$

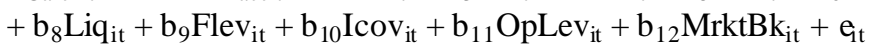

The naïve model assumes the next period's beta will be equal to the current period beta. The market average beta model assumes that the weighted average beta of the market is one. The industry average beta model assumes the next period beta will be equal to the current industry average beta. The sample is split into two industry groupings, extractive industries and non-extractive industries. The mean absolute error column also reports the t-test where a significant results indicates that the model is inferior to the accounting based model; ${ }^{*}$ indicates significance at the $10 \%$ level, ${ }^{* *}$ indicates significance at the $5 \%$ level, ${ }^{* * *}$ indicates significance at the $1 \%$ level. 


\section{Table 7}

The Long Term Association Between Accounting Risk Variables and Stock

Prices

\begin{tabular}{cccc}
\hline Panel A: Equation: & \multicolumn{3}{c}{} \\
$\beta_{i t}=\alpha_{1}+\alpha_{2}$ Accbeta $_{i t}+\alpha_{3} E V_{i t}+\alpha_{2} E S_{i t}+\alpha_{4}$ Grth $_{i t}+\alpha_{5}$ & Flev & \\
Year & $\mathbf{R}^{2}$ & $\alpha_{6}$ Size $_{i t}+\alpha_{7}$ Oplev $_{i t}+\alpha_{8}$ Liq $_{i t}$ \\
1977 & .25 & Year & $\mathbf{R}^{2}$ \\
\hline 1978 & .32 & 1990 & .45 \\
1979 & .25 & 1991 & .36 \\
1980 & .56 & 1992 & .39 \\
1981 & .45 & 1993 & .38 \\
1982 & .54 & 1994 & .43 \\
1983 & .60 & 1995 & .41 \\
1984 & .74 & 1996 & .41 \\
1985 & .47 & 1997 & .35 \\
1986 & .42 & 1998 & .32 \\
1987 & .34 & 1999 & .32 \\
1988 & .43 & 2000 & .26 \\
1989 & .34 & 2001 & .28 \\
& & &
\end{tabular}

Panel B: Time Regression: $\overline{R_{t}^{2}}=\phi_{0}+\phi_{1} T I M E+\varepsilon_{i t}$

\begin{tabular}{ccll} 
Model & Alpha & Time & $\mathbf{R}^{2}$ \\
\hline 4 & $10.424^{*}$ & -.005 & .06 \\
\hline
\end{tabular}

This table presents summary yearly regression results over the period 1974 to 2001. Statistics reported are adjusted $R^{2}$ regression statistics. All accounting variables are scaled by market value as per Brown Lo and Lys (1999). 